\title{
Старение населения как угроза бюджетного кризиса: актуарный анализ
}

А.К. СолОвьЁв, доктор экономических наук, Финансовый университет при Правительстве РФ, Заслуженный экономист РФ, Москва.

E-mail: sol26@100.pfr.ru

Глобальный демографический кризис (сокращение рождаемости и смертности одновременно с ростом продолжительности жизни и увеличением численности пенсионеров) нередко используется для обоснования государственной поддержки бизнеса за счет ограничения «необоснованно растущих социальных расходов государства", в частности, неизбежности повышения пенсионного возраста. Поскольку на выплату пенсий по возрасту приходится четверть бюджетных расходов, то предотвращение угрозы бюджетного кризиса связывается с пенсионной системой, а показатель пенсионного возраста становится одним из бюджетоформирующих параметров в процессе стратегического планирования и прогнозирования.

Ключевые слова: пенсионеры, продолжительность жизни, пенсионный возраст, демография, страховая пенсия

\section{Пенсионный возраст как регулятор развития пенсионной системы}

В настоящее время в России наблюдается процесс старения населения по причине увеличения общей продолжительности жизни при рождении (ОПЖ) с 65,3 лет в 2000 г. (для обоих полов) до 70,93 лет в 2014 г., который сопровождается ростом общей численности пенсионеров с 32,84 млн чел. в 1990 г. до 41,45 млн чел. в 2014 г. Коэффициент старения (отношение численности людей в возрасте 60 лет и старше к общему числу населения) уже в 2010 г. был очень высок - 18,1\% и возрастет к 2050 г. до $30,2 \%$.

Закономерным результатом этого процесса является увеличение расходов на финансирование государственных пенсионных обязательств (табл. 1). Тем не менее тезис, что старение населения служит одной из причин бюджетного кризиса, и существует непосредственная и жесткая связь между расходами пенсионного бюджета, ростом численности пенсионеров и общим старением населения, выглядит убедительным только на первый взгляд. 


\section{Таблица 1. Динамика финансовой обеспеченности бюджета ПФР и трансфертов из федерального бюджета в 1991-2014 гг., млрд руб.}

\begin{tabular}{|l|c|c|c|c|c|c|c|l|l|}
\hline Показатель & $\mathbf{1 9 9 1}$ & $\mathbf{1 9 9 5}$ & $\mathbf{2 0 0 1}$ & $\mathbf{2 0 0 5}$ & $\mathbf{2 0 1 0}$ & $\mathbf{2 0 1 1}$ & $\mathbf{2 0 1 2}$ & $\mathbf{2 0 1 3}$ & $\mathbf{2 0 1 4}$ \\
\hline Доходы & 0,10 & 88,9 & 532,1 & 1349,6 & 4610,1 & 5255,6 & 5890,4 & 6388,4 & 6159,1 \\
\hline $\begin{array}{l}\text { В том числе распредели- } \\
\text { тельная составляющая }\end{array}$ & 0,10 & 88,9 & 532,1 & 1266,3 & 4248,9 & 4837,5 & 5413,5 & 5798,2 & 6075,5 \\
\hline $\begin{array}{l}\text { Из них трансферты из фе- } \\
\text { дерального бюджета }\end{array}$ & 0,0 & 6,0 & 34,0 & 693,1 & 2645,9 & 2380,8 & 2815,6 & 2837,2 & 2400,6 \\
\hline Расходы & 0,09 & 88,7 & 514,8 & 1299,1 & 4249,2 & 4922,1 & 5451,2 & 6378,6 & 6190,6 \\
\hline $\begin{array}{l}\text { В том числе распредели- } \\
\text { тельная составляющая }\end{array}$ & 0,09 & 88,7 & 514,8 & 1297,8 & 4179,2 & 4681,6 & 5195,1 & 5986,9 & 6168,0 \\
\hline
\end{tabular}

Пенсионная система современного цивилизованного общества является интегральным индикатором уровня социальной ориентированности государства, определяемого такими показателями, как размер государственной пенсии и нормативно установленный возраст назначения пенсии по старости. Для нашей страны, где социально-ориентированная государственная система декларирована в Конституции, оба эти критерия принципиальны, поскольку отечественная пенсионная система встречает свой 25-летний юбилей в состоянии перехода к страховым инструментам. Старшее поколение пенсионеров еще не забыло «советские пенсии», практически не отличавшиеся от размера заработка, что при наличии общественных фондов потребления и общенародной собственности позволяло сохранять тот же уровень жизни, как и у граждан трудоспособного возраста. Это достигалось, с одной стороны, практически уравнительным размером пенсии, а с другой - финансированием из госбюджета.

Однако в рыночных отношениях пенсионные права формируются на основе «трудового вклада» каждого пенсионера в государственную пенсионную систему в течение всей трудоспособной жизни. Количественные критерии измерения этого вклада - показатели трудового стажа и заработной платы/дохода. При этом пенсионная система должна быть встроена в государственную систему управления в части бюджетного планирования, а значит, она полностью зависит от всех факторов, определяющих как макроэкономическое развитие страны, так и демографические процессы.

В таком контексте пенсионный возраст становится интегральным параметром страховой пенсионной системы, поскольку 
зависит как от характеристик самой государственной пенсионной программы, так и от институциональных факторов (продолжительность трудового стажа и размер заработка, подлежащего обязательному пенсионному страхованию). Эти параметры хотя и нормируются государством, но в полной мере зависят от самого застрахованного лица и должны заинтересовывать его в увеличении своих пенсионных прав.

Для актуарного обоснования пенсионного возраста, помимо выбора пропорций между продолжительностью трудового стажа и периодом выплаты (дожития), необходимо установить размер страховой пенсии, который мог бы обеспечить будущему пенсионеру «достойный уровень жизни пожилого человека», измеряемый соотношением с прожиточным минимумом пенсионера (ПМП), который до настоящего времени является единственным социальным нормативом пенсионного обеспечения. ПМП сейчас составляет около 1,7 прожиточных минимумов, и с учетом объективных факторов долгосрочного социально-экономического развития страны рассчитывать более чем на 2,5 ПМП для современного поколения застрахованных лиц не приходится.

Пенсионная система в цивилизованном обществе - не только и не столько потребитель бюджетных ресурсов, но прежде всего фактор устойчивого долгосрочного социально-экономического развития. Исходя из этого размер пенсии и продолжительность ее получения должны быть соотнесены со стажем работы и уплаченными страховыми взносами, чтобы, период получения страховой пенсии позволял полностью реализовать накопленные пенсионные права, а ее размер - обеспечивать достойный уровень жизни не только в момент ее назначения, но и на протяжении всего периода ее получения. Опережающий рост производительности труда относительно продолжительности жизни населения позволил всем западным странам осуществить повышение пенсионного возраста до 65 лет (даже без учета гендерных различий $\left.{ }^{1}\right)$. Эта проблема стоит и перед российской пенсионной системой. Однако она должна решаться с учетом нашей специфики - уникальной сложности самой этой системы, которая вследствие перманентных реформ накопила многочисленные

\footnotetext{
${ }^{1}$ В отдельныхстранахс относительно низким уровнем жизни сохранились незначительные льготы по возрасту для женщин.
} 
и институционально несовместимые обязательства государства перед различными категориями пенсионеров. Сложившаяся к настоящему времени система включает большое количество различных по своему экономическому и правовому содержанию пенсионных программ, охватывающих разные категории пенсионеров (досрочников, бюджетников, северян, сельхозработников, индивидуалов и проч.), пенсионные права которых формируются в разных условиях (тариф, стаж, база начисления, размеры выплаты). Вторая, более сложная проблема пенсионной системы РФ - отсутствие роста производительности труда по причине застоя в переходе к рыночной экономике - играет решающую роль в создании объективных условий институциональной реформы пенсионной системы. Далее рассмотрим макроэкономические и институциональные условия для изменения пенсионного возраста.

\section{Социальные условия для повышения пенсионного возраста}

С учетом значимости проблемы пенсионного возраста в Ocновных направлениях деятельности Правительства Российской Федерации на 2016-2018 гг. (утверждены 14 мая 2015 г.) намечено провести всесторонний анализ проблем повышения пенсионного возраста и на его основе - широкое обсуждение, чтобы определить его целесообразность для лиц, вновь выходящих на пенсию, а также возможных сроков и условий.

Отметим, что проблема пенсионного возраста была представлена для общенародного и правительственного обсуждения после опубликования научного доклада «Стратегии-2020: новая модель роста - новая социальная политика». В этом документе российской пенсионной системе придается едва ли не ключевая роль главного «драйвера» экономического роста. Это подчеркивается через постановку задачи создания «базовых условий роста макроэкономики», где реформированию пенсионной системы придается не меньшее значение, чем бюджетной и налоговой.

Однако в контексте «новой социальной политики» «Стратегии 2020» пенсионную систему рассматривают как самое слабое и рисковое звено всей макроэкономической системы государства. А причиной такой уязвимости предлагается считать опять же угрозу демографического кризиса - катастрофическое 
старение нашего населения, неконтролируемый рост численности пенсионеров, которые являются непосильной и неоправданной обузой для всей экономики: «негативный демографический тренд - это стратегический долгосрочный вызов государству».

Среди инструментов регулирования пенсионной системы (стаж, заработок, взносы, льготы и т. д.) законодательно нормируемый «пенсионный возраст» занимает особое место, поскольку его изменение сопровождается отложенным эффектом и многочисленными косвенными последствиями. Пенсионный возраст должен рассматриваться, как это практикуется в западных развитых пенсионных системах, в качестве одного из базовых экономических инструментов, поскольку именно он автоматически приводит к изменению всех звеньев пенсионной системы, в первую очередь - процесса формирования пенсионных прав, усиливая или сокращая экономический механизм солидарного перераспределения пенсионных прав между всеми категориями пенсионеров - как настоящих, так и будущих. Поэтому повышению пенсионного возраста должна предшествовать (либо сопровождать его) институциональная реформа, обеспечивающая, с одной стороны, эквивалентность размера пенсии продолжительности стажа и заработку, а также минимальный уровень материального обеспечения.

Для решения задачи эквивалентности расчетные параметры увеличения продолжительности трудового стажа и сокращения периода выплаты при повышении пенсионного возраста должны быть скорректированы с учетом требований, сформулированных в рекомендациях международных организаций относительно минимальных норм пенсионного обеспечения. Это касается широты охвата населения страны пенсионным страхованием, условий и ограничений доступа в пенсионную систему, степени удовлетворенности размером пенсионных выплат и др.

Объективное условие для повышения пенсионного возраста его адаптация к макроэкономическим параметрам развития экономики страны, как современным, так и в долгосрочной перспективе. На практике это означает, во-первых, создание новых дополнительных рабочих мест для всех категорий граждан предпенсионного возраста, независимо от возможности продолжения их трудовой деятельности, что обусловлено растущим «дефицитом» трудового стажа (недостаток стажа относительно необходимой 
его продолжительности для получения среднестатистического размера пенсии) для формирования пенсионных прав, в основном у женщин ${ }^{2}$.

Результаты актуарных расчетов необходимой продолжительности трудового стажа, позволяющего получать страховую пенсию в размере, адекватном современным представлениям об уровне жизни среднестатистического пенсионера (2,5 ПМП) в течение всего периода дожития, показывают существенные отклонения от прогнозируемых макроэкономических и демографических параметров. Поскольку наиболее уязвимым звеном в проблеме повышения возраста является низкая продолжительность жизни после назначения пенсии у мужчин, в расчетах сохранен установленный пенсионный возраст. Однако даже при сохранении нынешнего пенсионного возраста мужчины не могут реализовать более четверти накопленных пенсионных прав, поскольку для этого период дожития должен составлять 19,3 года.

Для женщин проблема противоположная: даже при сокращении периода выплаты почти на четверть им необходимо увеличивать возраст назначения пенсии на шесть лет. При этом у них наблюдается очень серьезный недостаток трудового стажа: для формирования необходимого объема пенсионных прав они должны трудиться более 36 лет (сейчас - не более 28-30 лет).

Отсюда закономерно вытекает вывод о необходимости либо дополнительно увеличивать пенсионный возраст, либо снижать пенсии. Зарабатывание дополнительных прав в период работы после назначения страховой пенсии не решает проблемы, поскольку может только частично компенсировать рост расходов на увеличивающийся период дожития. В настоящее время данная коллизия решается благодаря солидарно-гендерному перераспределению пенсионных прав между мужчинами и женщинами, поскольку соотношение трудового стажа и периода выплаты у мужчин почти на треть лучше, чем у женщин (табл. 2).

Особенно наглядно проблема сокращения продолжительности периода формирования пенсионных прав видна при сравнении фактической продолжительности стажа на общих основаниях до и после страховой реформы 2002 г.: разница составляет более

${ }^{2}$ C учетом прогнозов рынка труда проблема недостатка стажа для формирования даже минимального объема пенсионных прав к середине 2010-х годов коснется и мужчин. 
четырех лет (34,79 и 30,56 лет). Притом, что продолжительность стажа при назначении пенсии по инвалидности и по случаю потери кормильца практически не изменилась.

\section{Таблица 2. Необходимая продолжительность трудового стажа для формирования пенсионных прав в заданном размере, лет}

\begin{tabular}{|l|c|c|c|}
\hline \multicolumn{1}{|c|}{ Показатель } & $\begin{array}{c}\text { Мужчи- } \\
\text { ны }\end{array}$ & $\begin{array}{c}\text { Женщи- } \\
\text { ны }\end{array}$ & $\begin{array}{c}\text { Оба } \\
\text { пола }\end{array}$ \\
\hline $\begin{array}{l}\text { Необходимый стаж для получения заданного размера пенсии к уста- } \\
\text { новленному возрасту }\end{array}$ & 34,9 & 36,1 & 35,2 \\
\hline $\begin{array}{l}\text { Ожидаемая продолжительность периода выплаты, которая обеспече- } \\
\text { на накопленными пенсионными правами застрахованных лиц }\end{array}$ & 19,3 & 20 & 19,5 \\
\hline $\begin{array}{l}\text { Пенсионный возраст, } \\
\text { который обеспечивает эквивалентность прав и обязательств }\end{array}$ & 60 & 61 & 60 \\
\hline
\end{tabular}

* Для мужчин - 15,3 года.

Аналогичная тенденция сохраняется и до настоящего времени. Так, за период после 2002 г. общая численность застрахованных лиц, формирующих пенсионные права, снизилась более чем на 13\% для лиц трудоспособного возраста, при одновременном росте занятости в нетрудоспособном возрасте.

Следует подчеркнуть, что дефицит формирования пенсионных прав наиболее сильно повлияет на застрахованных лиц в возрасте 16-25 лет, практически без гендерных различий. В то время как в более старших возрастах доля застрахованных лиц трудоспособного возраста, не формирующих пенсионные права, начиная с 2002 г., составляет 12-13\%, причем со значительным превышением у мужчин. Наблюдается существенное превышение женской занятости в период после общеустановленного возраста назначения пенсии на общих основаниях.

Рост хронической незанятости негативно влияет не только на размеры пенсий, но и на сокращение доходов пенсионного бюджета. Численность застрахованных лиц трудоспособного возраста, не формировавших пенсионные права в отчетном году (т. е. величина текущей незанятости), возросла с 19 млн чел. в 2002 г. до 31 млн чел. в 2011 г. (на 62,5\%). А доля незанятых в численности зарегистрированных в СПУ застрахованных лиц трудоспособного возраста увеличилась за 10 лет с 25,6\% до 35,3\%.

Еще один важный аспект - из общего числа наемных работников полный год заняты только 68\% женщин и 60\% мужчин, остальные работают менее года. Более того, в 2011 г. 
$9 \%$ работавших женщин и $12 \%$ мужчин в течение года были заняты менее шести месяцев (табл. 3). Это создает риски сокращения охвата государственным пенсионным страхованием и недополучения доходов бюджета ПФР.

Таблица 3. Продолжительность периода занятости наемных работников в течение года, \%

\begin{tabular}{|l|c|c|c|c|c|c|c|c|c|c|}
\hline \multirow{1}{*}{ Период } & $\mathbf{2 0 0 2}$ & $\mathbf{2 0 0 3}$ & $\mathbf{2 0 0 4}$ & $\mathbf{2 0 0 5}$ & $\mathbf{2 0 0 6}$ & $\mathbf{2 0 0 7}$ & $\mathbf{2 0 0 8}$ & $\mathbf{2 0 0 9}$ & $\mathbf{2 0 1 0}$ & $\mathbf{2 0 1 1}$ \\
\cline { 2 - 11 } & \multicolumn{10}{|c|}{ Женцины 20-54 лет } \\
\hline 1 год & 75,0 & 74,8 & 74,6 & 74,5 & 73,0 & 72,3 & 72,3 & 73,5 & 71,3 & 68,1 \\
\hline 6-11 мес. & 13,6 & 14,0 & 14,4 & 14,5 & 15,6 & 16,4 & 16,9 & 15,0 & 20,0 & 22,8 \\
\hline Менее 6 мес. & 11,4 & 11,1 & 11,0 & 11,1 & 11,5 & 11,3 & 10,7 & 11,5 & 8,8 & 9,1 \\
\hline & \multicolumn{10}{|c|}{ Мужчины $20-59$ лет } \\
\hline 1 год & 64,2 & 64,0 & 64,3 & 64,8 & 63,7 & 62,6 & 62,5 & 64,0 & 62,1 & 59,8 \\
\hline 6-11 мес. & 19,3 & 19,7 & 19,7 & 19,6 & 20,4 & 21,3 & 22,0 & 19,3 & 25,8 & 28,1 \\
\hline Менее 6 мес. & 16,5 & 16,3 & 16,0 & 15,6 & 15,9 & 16,0 & 15,5 & 16,7 & 12,1 & 12,2 \\
\hline
\end{tabular}

Источник: расчеты автора.

Из общего числа застрахованных лица трудоспособного возраста составляют около 14,4 млн $(16,4 \%)$. Без учета неработающих получателей трудовой пенсии по инвалидности численность лиц трудоспособного возраста, не имеющих страхового стажа с 2002 г. (т. е. незанятых в течение полного 10-летнего периода), составила на 2011 г. 12,7 млн чел.

Для оценки потери пенсионных прав застрахованных лиц от хронической незанятости рассмотрим их группировку по возрасту. Так, за 2002-2011 гг. из тех, кому до достижения пенсионного возраста осталось 10-15 лет, не имеют ни одного дня стажа $14,4 \%$ мужчин и $11,6 \%$ женщин; из тех, кому до пенсии не более пяти лет, $-15,2 \%$ мужчин и $12,1 \%$ женщин. Очевидно, что в оставшееся до пенсионного возраста время они не успеют выработать необходимый стаж и станут получателями социальных пенсий спустя пять лет после достижения общеустановленного пенсионного возраста. В долгосрочной перспективе это приведет к росту числа бедных пенсионеров, что потребует целевого финансирования за счет средств федерального бюджета.

Таким образом, проблема пенсионного возраста как главной угрозы неоправданного увеличения расходов федерального бюджета не может рассматриваться в рамках линейной зависимости от демографических показателей общей продолжительности жизни, она непосредственно 
взаимосвязана с комплексом социально-трудовых факторов и макроэкономических условий.

\section{Экономические риски}

\section{повышения пенсионного возраста}

Актуарный анализ показывает, что социальные и экономические риски роста численности пенсионеров существенно меньше, чем риски опережающего сжатия рынка труда, в первую очередь «легального». Так, за период после пенсионной реформы количество застрахованных работников снизилось на 13\% при одновременном росте числа пенсионеров по старости только на 5,5\% (табл. 4). Подчеркнем, что рост нагрузки на трудоспособное население достигается за счет женщин. Аналогичная тенденция сохранится и на весь период реализации Стратегии долгосрочного развития пенсионной системы.

\section{Таблица 4. Динамика изменения численности застрахованных лиц, формирующих пенсионные права, за период пенсионной реформы, \%}

\begin{tabular}{|c|l|c|c|}
\hline \multirow{2}{*}{ год } & Пол & Трудоспособный возраст & Старше трудоспособного \\
\hline \multirow{3}{*}{2002} & Женщины & 75,7 & 18,0 \\
\cline { 2 - 4 } & Мужчины & 72,7 & 25,8 \\
\cline { 2 - 4 } & Оба пола & 74,3 & 20,1 \\
\hline \multirow{3}{*}{2014} & Женщины & 64,4 & 26,8 \\
\cline { 2 - 4 } & Мужчины & 59,8 & 25,1 \\
\cline { 2 - 4 } & Оба пола & 61,2 & 25,7 \\
\hline
\end{tabular}

* Женщины 16-54 лет, мужчины 16-59 лет.

С учетом указанного комплекса проблем рассмотрим главный фактор повышения пенсионного возраста - рост продолжительности жизни и соответственно - количества пенсионеров, которые создают дополнительную нагрузку как на бизнес, так и на госбюджет. В пример приводится повышение пенсионного возраста в странах Запада. Но стратегия развития западных страховых пенсионных систем направлена на расиирение охвата участников таких систем - как государственных, так и негосударственных. При этом ставится цель сокращения «нестраховых» социальных выплат (многочисленные виды пособий, льгот, дотаций и т. п.) и их замещения страховыми инструментами социальной защиты (но не секвестирования или ликвидации 
социальных гарантий). Для этого социальное государство создает комплекс организационных и правовых условий и экономических стимулов, чтобы гражданам было выгодно самостоятельно формировать свое материальное благополучие в старости и др.

У нас же наблюдается противоположная тенденция: вместо советской системы всеобщего пенсионного обеспечения (пусть и относительно уравнительного, т. е. без учета индивидуального трудового вклада) четверть века наблюдается тенденция сокращения, а после 2015 г. - прямого отторжения из системы государственного пенсионного страхования застрахованных лиц, которые не смогут сформировать даже минимально необходимые пенсионные права на получение государственных социальных гарантий (минимальные период стажа и сумма баллов) ${ }^{3}$.

К тому же для повышения пенсионного возраста практически во всех странах ОЭСР, в отличие от России, есть существенные резервы как по демографическим, так и по макроэкономическим условиям. Так, ожидаемая продолжительность жизни при рождении для мужчин существенно превышает 70 лет, для женщин далеко за 80 лет. В России же такого демографического резерва нет и не предвидится: ожидаемая продолжительность жизни составляет 62 и 74 года соответственно (2014 г.). В странах ОЭСР в возрасте 65 лет ожидаемая продолжительность жизни для мужчин - около 18 лет, для женщин - почти 22 года. В России у мужчин даже в возрасте 60 лет она ниже, чем в ОЭСР в 65 лет. В результате этого из числа мужчин, которым в настоящее время 20 лет, до 60 лет доживут 60,8\% (т. е. умрут 39,2\%), и в течение последующих пяти лет из оставшихся 60-летних мужчин умрут еще $18 \%$. Из 20-летних женщин до 60 лет доживут 85,6\% и в течение последующих пяти лет умрут еще $7 \%$.

В настоящее время уровень занятости в возрастных группах, подпадающих под повышение пенсионного возраста, варьируется в пределах: для женщин - от 62 до $28 \%$, и мужчин - от 58 до $49 \%$ (быстро понижаясь по возрастным группам: 55-60 лет для женщин и 60-65 лет - для мужчин, соответственно).

${ }^{3}$ В настоящее время доля застрахованных лиц, которые в течение всего трудового периода не обеспечивают себе прожиточный минимум пенсионера, составляет десятую часть пенсионеров, а с учетом усиления требований к стажу и заработку их доля к концу пенсионной реформы увеличится до $15-17 \%$. 
Увеличение пенсионного возраста в указанных границах повлечет пропорциональное сокращение занятости на 5,9-39,7 п.п. и на 7,5-22,6 п. п. соответственно. Учитывая резко возрастающий после достижения нынешнего пенсионного возраста уровень инвалидизации, вероятнее всего, что уровень занятости и, соответственно, увеличение численности работающих в возрастных группах, подпавших под повышение пенсионного возраста, будет ниже, чем прогнозируется.

Эти данные свидетельствуют о том, что в России, в отличие от стран ОЭСР, повышение пенсионного возраста приведет к тому, что большая часть застрахованных лиц в увеличенный возрастной период, с одной стороны, не сможет эффективно формировать дополнительные пенсионные права для увеличения своей страховой пенсии, а с другой - не сможет их реализовать по причине смертности. Приведенные сопоставительные характеристики демографической нагрузки будут неполными, если не учесть существенную корректировку, которую вносит учет при таких сопоставлениях российских льгот (по видам деятельности, по возрасту и стажу застрахованных лиц, проживающих на Севере, работающих на вредных и опасных рабочих местах, пенсионеров-«бюджетников» и т. д.). Сопоставление с западными характеристиками свидетельствует о некорректности «прямолинейного» применения критериев развитых страховых пенсионных систем, поскольку необходимо учитывать уникальность российского пенсионного обеспечения, а также сопоставимость исходных параметров.

Важно отметить, что главный аргумент в пользу повышения пенсионного возраста - утверждение о катастрофическом росте пенсионной нагрузки на экономику - требует принципиального уточнения на основе объективной структуры отечественной пенсионной системы. Так, в целом на 100 человек трудоспособного возраста приходится 43 пенсионера, из них 40 чел. - получатели трудовых пенсий и три - пенсии по государственному пенсионному обеспечению. Однако из общего числа получателей страховых пенсий (15,8 млн чел.) 10,3 млн чел. - получатели досрочных пенсий по старости, не достигшие общеустановленного пенсионного возраста, 3,9 млн чел. - пенсий по инвалидности, 1,7 млн чел. - пенсий по случаю потери кормильца. В результате демографическая нагрузка пенсионеров на все занятое население 
при действующем пенсионном возрасте составит уже $38,4 \%$, а при возрасте, принятом в ОЭСР, всего $22,1 \%$; в расчете на пенсионеров по старости (без инвалидов и получающих пенсии по случаю потери кормильца, досрочников, северян и работающих пенсионеров) - $21 \%$ (в расчете на возраст ОЭСР - $15 \%$ ).

\section{Бюджетные последствия повышения пенсионного возраста}

С учетом приведенной статистики рассмотрим экономические последствия повышения пенсионного возраста.

Базовым, исходным для всех экономических расчетов показателем является сокращение численности пенсионеров (рис. 1). $\mathrm{C}$ позиций «экономии бюджетных расходов» этот показатель дает положительный эффект с первого же дня. Однако с позиций второго критерия эффективности пенсионной реформы повышения уровня жизни пенсионеров - требуется серьезная конкретизация.

Млн чел.

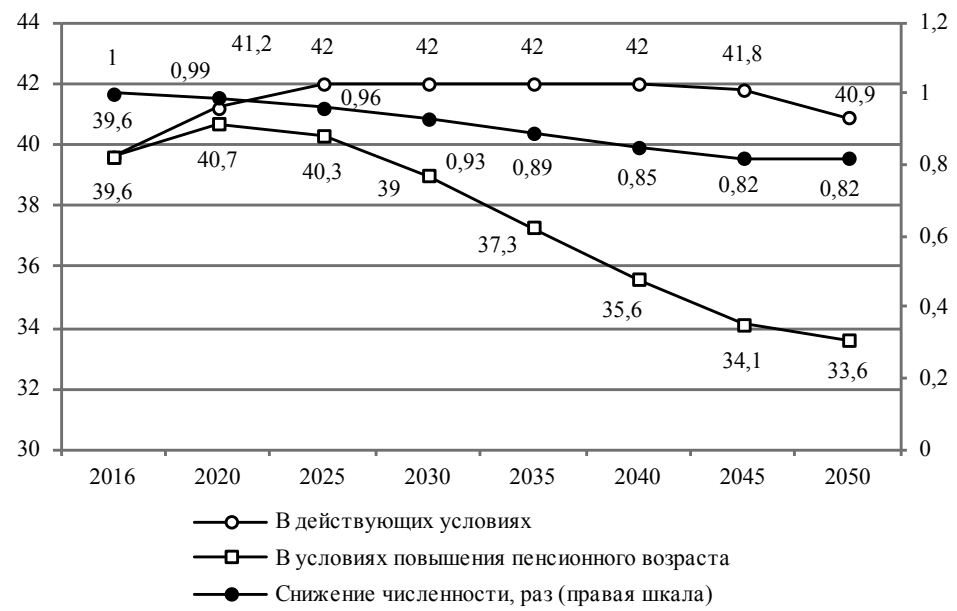

Рис.1. Прогноз сокращения численности пенсионеров при повышении пенсионного возраста в 2016-2050 гг., млн чел.

Во-первых, низкая ожидаемая продолжительность жизни, особенно у мужчин, приведет к тому, что часть застрахованных 
лиц не доживет до момента пенсии и не сможет воспользоваться своими пенсионными правами. Во-вторых, высокий уровень инвалидизации населения при повышении общеустановленного пенсионного возраста вызовет резкий скачок числа получателей пенсий по инвалидности.

В результате актуарные расчеты показывают, что незначительный (не выше 10-13\% расходов на выплату трудовых пенсий) экономический эффект от повышения пенсионного возраста может наблюдаться лишь в первые 10-15 лет (в зависимости от варианта повышения возраста), после чего пенсионная система начнет нести дополнительные расходы (рис. 2).

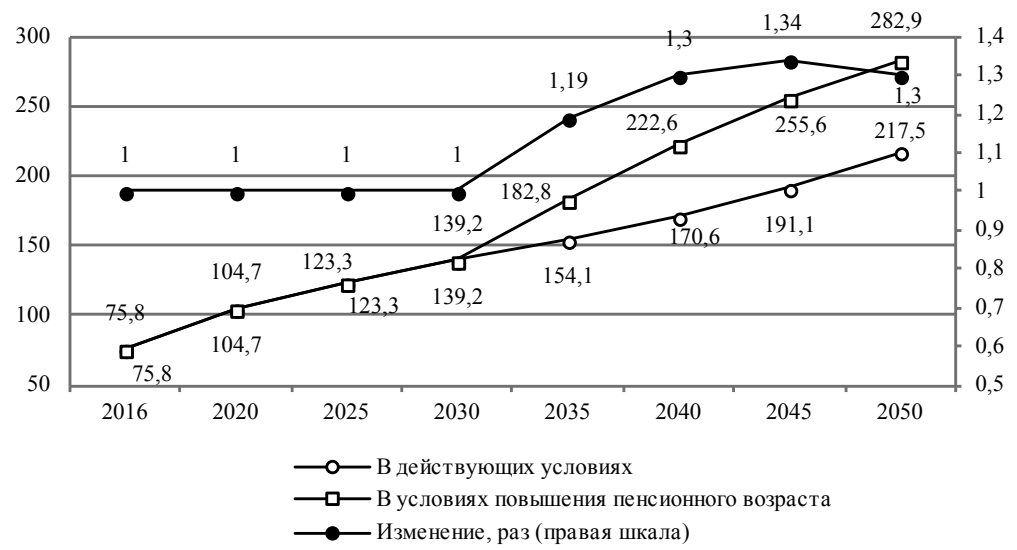

Рис.2. Прогноз роста стоимости балла индивидуального пенсионного коэффициента при повышении пенсионного возраста в 2016-2050 гг.

Макроэкономический прогноз рынка труда ориентирован на сокращение численности рабочих мест, что не позволит собрать доходы в объеме, достаточном для финансирования текущих обязательств без привлечения дополнительных трансфертов.

В результате индексация страховой пенсии до 2030 г. должна осуществляться только в рамках инфляции (из-за недостатка страховых доходов). В свою очередь экономические условия для страховой индексации после 2030 г. будут увеличивать расходы, и к концу переходного периода расходы на выплату пенсий по разным вариантам повышения пенсионного возраста 
превысят расходы по действующей системе на 5-15\%, а на выплату страховой пенсии без учета фиксированной выплаты к ней - на 20-35\% (рис. 3).

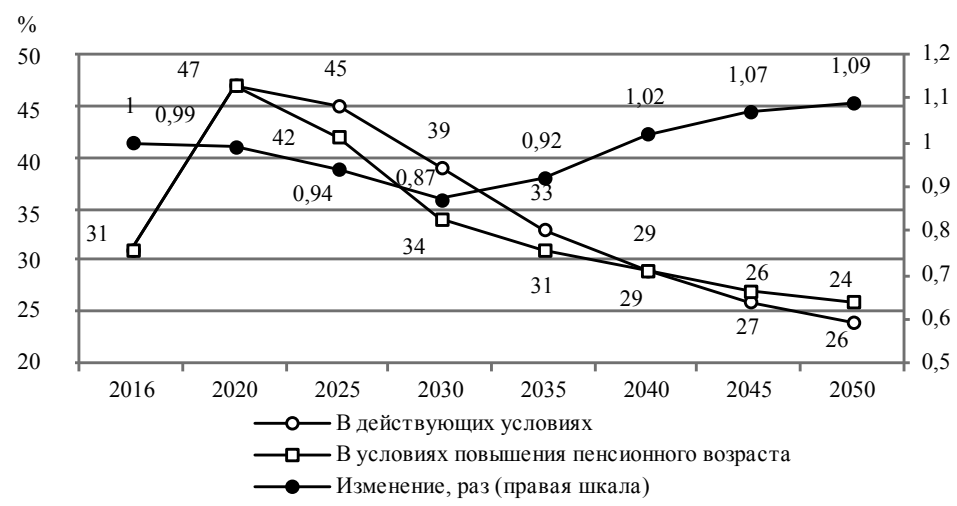

Рис. 3. Прогноз динамики трансфертов (левая шкала) при повышении пенсионного возраста при сохранении сложившихся макроэкономических пропорций в 2016-2050 гг., \%

Объем дополнительных бюджетных расходов (трансфертов федерального бюджета) уже к концу 2020-х годов будет превышать базовый вариант (без увеличения пенсионного возраста) на $10-15 \%$.

\section{Макроэкономические предпосылки повышения пенсионного возраста}

Актуарный анализ последствий повышения пенсионного возраста показывает, что сам по себе демографический фактор увеличение продолжительности жизни и сокращение рождаемости - не является определяющим в принятии управленческих решений по его изменению в ту или иную сторону, поскольку не в меньшей, а в нашей стране - в большей степени - экономические и социальные параметры пенсионной системы зависят от макроэкономических («внешних») и институциональных («внутренних») факторов ее развития.

Более того, даже главный пенсионный показатель - период выплаты страховой пенсии - в конкретных исторических 
условиях не дает прямых оснований для повышения пенсионного возраста.

Адаптацию пенсионной системы к демографической динамике должны сопровождать следующие адекватные государственные меры по регулированию макроэкономических и институциональных факторов.

- Снижение смертности в трудоспособных возрастах, в том числе путем развития социальных институтов, улучшения медицинского обслуживания, профилактики здоровья населения, диагностики смертельно опасных болезней на ранних стадиях (уменьшится назначение трудовых пенсий по случаю потери кормильца).

- Снижение инвалидности в трудоспособных возрастах, в том числе за счет уменьшения числа рабочих мест с вредными и тяжелыми условиями труда, приводящими к утрате работником здоровья и трудоспособности, улучшение условий и охраны труда (уменьшится назначение трудовых пенсий по инвалидности).

- Повышение рождаемости (не только за счет дополнительных мер государственной поддержки семей, имеющих детей, в виде выплаты материнского (семейного) капитала, но и с помощью пропаганды ценностей семьи, имеющей нескольких детей, а также различных форм семейного устройства детей, оставшихся без попечения родителей, чтобы сформировать в обществе позитивный образ семьи со стабильным зарегистрированным браком супругов, имеющих нескольких детей или принимающих на воспитание детей, оставшихся без попечения родителей).

- Для наемных работников, занятых на рабочих местах с особыми и вредными условиями труда, надо создавать обязательные профессиональные пенсионные системы и/или устанавливать для их работодателей дополнительный тариф страховых взносов в систему обязательного пенсионного страхования, чтобы компенсировать выплату этим работникам трудовых пенсий в период до достижения общеустановленного пенсионного возраста.

- Создание экономических и правовых условий, позволяющих обеспечить достойный уровень материального обеспечения при наступлении старости для страхователей, уплачивающих страховые взносы в ПФР в виде фиксированного платежа (их численность - 2 млн чел.): необходимо уплачивать не минимум, а сумму, достаточную для получения пенсии в течение 
всего периода выплаты пенсии, в размере не ниже прожиточного минимума пенсионера.

Особое место в проблеме повышения пенсионного возраста занимают индивидуальные предприниматели, которые после новой пенсионной реформы должны не только вырабатывать увеличенный (до 15 лет) минимальный пенсионный стаж, но и зарабатывать минимальный норматив индивидуальных пенсионных коэффициентов (ИПК).

Для этого каждый застрахованный предприниматель должен вносить в ПФР фиксированный платеж - в 2015 г. был установлен в размере 18,6 тыс. руб. (или ежемесячно - 1550,9 руб.) с последующей ежегодной индексацией. Однако уплата плательщиком страховых взносов в указанном размере фиксированного платежа в течение 15 лет (нормативный минимальный стаж для назначения страховой пенсии по старости) не позволит сформировать нормативную сумму - 30 баллов ИПК, что является вторым необходимым требованием для получения страховой пенсии. В результате он может рассчитывать только на социальную пенсию, которая назначается на пять лет позже и в минимальном размере - прожиточного минимума пенсионеров (ПМП).

Чтобы накопить минимум баллов, индивидуальный предприниматель должен работать 43 года.

По действующему статистическому прогнозу в соответствии с Концепцией демографического развития России, 60-летние мужчины достигнут текущей ожидаемой продолжительности жизни в странах ОЭСР 4 для 65-летних мужчин лишь к 2030-м годам (табл. 5). Только тогда повышение пенсионного возраста станет экономически и социально оправданным, поскольку застрахованные смогут использовать свои пенсионные права.

\section{Таблица 5. Прогноз продолжительности жизни пенсионеров} в 2015-2030 гг., лет

\begin{tabular}{|l|c|c|c|c|c|c|c|c|}
\hline \multicolumn{1}{|c|}{ Показатель } & $\mathbf{2 0 1 5}$ & $\mathbf{2 0 1 6}$ & $\mathbf{2 0 1 7}$ & $\mathbf{2 0 1 8}$ & $\mathbf{2 0 1 9}$ & $\mathbf{2 0 2 0}$ & $\mathbf{2 0 2 5}$ & $\mathbf{2 0 3 0}$ \\
\hline $\begin{array}{l}\text { Для населения в возрасте } \\
\text { выхода на пенсию }\end{array}$ & 21,5 & 22,2 & 22,1 & 22,0 & 22,0 & 21,9 & 22,7 & 23,3 \\
\hline 60-летних мужчин & 16,0 & 16,9 & 17,0 & 17,1 & 17,2 & 17,3 & 17,6 & 17,9 \\
\hline 55-летних женщин & 25,3 & 25,8 & 25,9 & 26,0 & 26,2 & 26,3 & 26,8 & 27,2 \\
\hline
\end{tabular}

\footnotetext{
${ }^{4}$ Естественно, что продолжительность соответствующего периода жизни в странах ОЭСР к 2030 г. также будет превышать российские показатели.
} 


\section{Актуарная оценка повышения пенсионного возраста: условия и результаты}

Актуарные расчеты показывают, что повышение пенсионного возраста целесообразно лишь в случае, когда его экономическим результатом станет решение не только конъюнктурных задач текущего бюджетного процесса, но и достижение долгосрочной сбалансированности пенсионной системы и ее устойчивости в течение всего периода формирования пенсионных прав и реализации государственных пенсионных обязательств. При этом, конечно, на первом плане должна быть главная социальная функция государственной пенсионной системы - достойный уровень материального обеспечения всех категорий пенсионеров при условии сохранения всеобщего охвата пенсионным обеспечением и равной доступности различных сфер занятости для формирования пенсионных прав.

Повышение пенсионного возраста благодаря прямому сокращению числа назначенных пенсий обеспечивает пропорциональное снижение расходов ПФР, причем в максимальном размере в первые 5-10 лет. Например, при увеличении возраста на полгода в год до 65 лет (для мужчин и женщин), начиная с 2016 г. (а завершится к 2045 г.), расходы бюджета ПФР будут ниже, чем в действующих условиях до 2028 г. (в 2020 г. - на 677 млрд руб., т. е. на 7,4\%, в 2025 г. - на 559 млрд руб., т. е. на 4,8\%). Но уже с 2029 г. расходы ПФР по этому варианту будут выше, чем в действующих условиях, на 1,3\%, а к 2050 г. - на 5,6\%.

Экономия в первые годы переходного периода будет в большей степени связана с сокращением расходов на страховую пенсию, а с середины периода - на фиксированную выплату к ней. При этом расходы на фиксированную выплату всегда будут ниже, чем в базовом (без увеличения возраста) варианте (в 2020 г. - на 6\%, в 2050 г. - на 23\%).

Расходы на страховую пенсию превысят уровень базового (без увеличения возраста) варианта в 2026 г. на 2,2\% (147 млрд руб.), в 2040 г. - на $18 \%$, а к концу прогнозного периода - на $22 \%$ (на 3,25 трлн руб.).

Трансферты федерального бюджета (см. рис. 2) при повышении пенсионного возраста также сначала снизятся, а затем - вырастут до уровня, превышающего базовый вариант. По базовому варианту трансферт постепенно снизится с 35\% в 2016 г. до 23\% 
в 2050 г., при этом его абсолютная величина будет непрерывно расти с 2,4 до 5,4 трлн руб.

При повышении пенсионного возраста к 2025 г. суммарный объем трансферта приблизится к уровню базовых расходов и будет их превышать нарастающими темпами. В 2050 г. сумма трансферта превысит базовый вариант почти на четверть (23\%). При этом существенно трансформируется структура федерального трансферта по отдельным его компонентам. Так, трансферт на валоризацию будет превышать базовый вариант начиная с 2023 г. (на 2,5\%), и к 2044 г. это превышение достигнет максимума (43\%). Трансферт на компенсацию выпадающих доходов бюджета ПФР в связи с установлением пониженных тарифов страховых взносов превысит уровень базового года уже в 2018 г. (на 0,8\%), в 2029 г. превышение достигнет $2 \%$ от объема соответствующего трансферта по базовому варианту и в дальнейшем будет сохраняться на этом уровне. Трансферт на обязательное пенсионное страхование до 2020 г. будет ниже уровня базового варианта (в 2020 г. на 24\%), но уже с 2027 г. превысит его на 4\%. В последующие годы сумма превышения будет варьировать на уровне 4-9\%, a с 2042 г. превысит $20 \%$ и к концу прогнозного периода достигнет $38 \%$. Особое влияние повышение пенсионного возраста оказывает на индексацию пенсий. В современных макроэкономических условиях по причине недостатка собственных доходов индексация может осуществляться только по темпам инфляции (т. е. в феврале следующего года) вплоть до конца 2020-х годов.

В условиях увеличения пенсионного возраста повышение стоимости балла (индивидуального пенсионного коэффициента) в соответствии с ростом доходов ожидается уже середине второго десятилетия (см. рис. 3). В последующие годы вплоть до середины столетия его индексация при увеличении возраста сохранится выше, чем в базовом варианте.

Изменение расходной части бюджета ПФР зависит от изменения численности пенсионеров и роста уровня пенсий.

Повышение пенсионного возраста коснется, в основном, получателей пенсий по старости, занятых в нормальных условиях труда. Возможности его увеличения для занятых в неблагоприятных природно-климатических и производственно-технологических условиях необходимо рассматривать с учетом влияния указанных факторов на их здоровье и трудоспособность. В первый год не доживут до нового пенсионного возраста 15,4 тыс. чел., 
а в последний год переходного периода и последующие годы ежегодно 144 тыс. чел. в возрасте 55(60)-64 лет. В общей сложности за переходный период умрут, не начав получать пенсии в новом пенсионном возрасте, 3,9 млн чел.

Численность получателей страховой пенсии снизится в 2020 г. на 2,9 млн чел., в 2030 г. - на 6,2 млн чел., в 2045 г. на 11,8 млн чел. по сравнению с базовым вариантом. Причем сокращаться будет численность пенсионеров по старости, тогда как по инвалидности - расти вследствие возрастающего уровня инвалидизации в пожилых возрастах.

На протяжении всего переходного периода средний размер страховой пенсии (в том числе пенсии по старости) будет выше, чем в базовом варианте, в том числе по окончании прогнозного периода, к 2040-м годам, - соответственно на 39\% и 44\%.

Помимо непосредственных результатов для бюджетной системы ПФР, повышение возраста будет сопровождаться вторичными экономическими последствиями. Перестройка пенсионной системы повлияет на расходы федерального и региональных бюджетов или соответствующих внебюджетных фондов, во-первых, в связи с сокращением высвобождающихся рабочих мест, вырастет молодежная безработица и возникнут дополнительные расходы на выплату пособий по безработице и на уплату страховых взносов на обязательные медицинское и социальное страхование; во-вторых, из-за повышения расходов на медицинское обслуживание работающих пожилых людей (что увеличит нагрузку на фонды ОМС по лечению пожилых людей и на оплату больничных листов).

Кроме того, возникнет ряд дополнительных расходов на ежемесячные денежные выплаты лицам, которые будут выходить на пенсию по инвалидности в возрасте между 55/60 годами и новым пенсионным возрастом, на содержание в яслях и детских садах детей, чьи бабушки будут вынуждены продолжить работу, и на медицинское обслуживание этих детей, поскольку заболеваемость детей, посещающих детские учреждения, выше, чем находящихся на домашнем воспитании.

Чтобы смягчить ситуацию, необходимо создавать специальные рабочие места для людей пожилого возраста и для молодежи (правда, по макроэкономическим прогнозам в долгосрочной перспективе ожидается не увеличение, а сокращение рабочих 
мест), а также повысить тарифы страховых взносов на медицину и социальное страхование.

Расчеты объективно показывают, что одна из главных целей повышения пенсионного возраста - сокращение расходов федерального бюджета - достигается только в краткосрочном периоде, а затем расходы на увеличившийся объем пенсионных прав возрастают. Решение же стратегической задачи достижение долгосрочной сбалансированности и устойчивости пенсионной системы - возможно только при осуществлении комплекса мероприятий, касающихся как самой пенсионной системы, так и макроэкономических факторов, определяющих ее функционирование.

При этом главное направление «предотвращения демографической угрозы старения» и роста нагрузки на федеральный бюджет заключается не в сокращении численности пенсионеров и секвестировании их пенсионных прав, а в создании объективных условий на рынке труда для реализации трудовых прав граждан на занятость и, соответственно, на зарабатывание собственных пенсий.

\section{Список использованной литературы}

1. Кудрин А.Л., Гурвич Е. Т. Старение населения и угроза бюджетного кризиса// Вопросы экономики. - 2012. - № 3. - С. 52-79.

2. Соловьев А.К. Пенсионная реформа: иллюзии и реальность. - М.: Проспект, 2015.

3. Стратегия-2020. Новая модель роста - новая социальная политика. Итоговый доклад. Кн. 1. гл. 6. «Реформа пенсионной системы». - М.: Дело, 2013. - С. 197-228

4. Доклад Всемирного банка «Реформа системы пенсионного обеспечения в России: структура и реализация» 2008.

5. Доклад Всемирного банка «Перевернутая пирамида: системы пенсионного обеспечения перед лицом демографических проблем в странах Европы и центральной Азии». ВБ -2011.

6. Доклад МВФ по стране № 13/310. Российская Федерация. Консультации 2013 года в соответствии со статьей IV соглашения МВФ.

7. Основные направления деятельности Правительства Российской Федерации на период до 2018 года (новая редакция). Утверждены 14 мая 2015 года Правительством Российской Федерации.

8. Стратегия демографического развития РФ до 2050 г.

9. Аналитический доклад «Итоги пенсионной реформы и долгосрочные перспективы развития пенсионной системы РФ с учетом влияния мирового финансового кризиса». МЗСР - 2012.

10. Стратегия долгосрочного развития пенсионной системы Российской Федерации» утверждена Распоряжением Правительства РФ от 25.12.2012 № 2524-p. 